\title{
Alunos com deficiência física: cognições sobre suas habilidades sociais e de seus colegas
}

\author{
Students with physical disabilities: cognitions about their \\ social skills and colleagues
}

\section{Estudiantes con discapacidades físicas: cogniciones sobre sus habilidades sociales y colegas}

Sueley Carvalho Costa'

https://orcid.org/0000-0003-0727-294I

Irani Lauer Lellis²

http://orcid.org/0000-0002-5688-9887

\begin{abstract}
Resumo: Pesquisas em habilidades sociais (HS) de alunos com deficiência ainda se mostram timidamente no contexto da Educação Física. O objetivo deste trabalho é conhecer o que alunos com deficiência física pensam sobre suas HS e de seus colegas e sobre sua relação interpessoal nas aulas de Educação Física. Participaram cinco alunos com deficiência física não cadeirantes, de II a I5 anos, do ensino fundamental II, do $6^{\circ}$ ao $9^{\circ}$ ano, de cinco escolas municipais de Santarém-Pará. Para coleta de dados, foi utilizada a entrevista semiestruturada. Para análise de dados, foi utilizada a técnica do Discurso do Sujeito Coletivo. Os resultados apresentaram que os participantes reconhecem e compreendem suas HS e de seus colegas e concluem que seus colegas ainda têm atitudes de discriminação e exclusão por conta de sua condição física. Contudo, percebem que as HS estão presentes no contexto das aulas de Educação Física e favorecem o contexto inclusivo.
\end{abstract}

Palavras-chave: Habilidades sociais. Deficiência física. Educação Física.

\begin{abstract}
Research on social skills (Habilidades sociais -HS) of students with disabilities still shows itself timidly in the context of Physical Education. The objective of this work is to know what students with physical disabilities think about their HS and their colleagues and about their interpersonal relationship in Physical Education classes. Five students with physical disabilities who did not use a wheelchair, aged II to I 5 years, from elementary school II, from the 6th to the 9th grade, from five municipal schools in Santarém-Pará participated in this study. For data collection, a semi-structured interview was used. For data analysis, the Collective Subject Discourse technique was used. The results showed that participants recognize and understand their HS and their peers and conclude that their peers still have attitudes of discrimination and exclusion due to their physical condition. However, they realize that HS are present in the context of Physical Education classes and favor of the inclusive context.
\end{abstract}

Keywords: Social skills. Physical disability. Physical Education.

Resumen: Las investigaciones sobre habilidades sociales (HS) de alumnos con discapacidad todavía aparecen tímidamente en el contexto de la Educación Física. El objetivo de este trabajo es conocer qué piensan los alumnos con discapacidad física sobre sus HS, de sus compañeros y sobre su relación interpersonal en clases de Educación

\footnotetext{
${ }^{1}$ Mestre em Educação. Professora do ensino básico - SEDUC Pará. E-mail: sueleycarvalho@gmail.com.br.

${ }^{2}$ Doutora em Psicologia. Professora da Universidade Federal do Oeste do Pará. E-mail: iranilauer@gmail.com.
} 
Física. Participaron cinco estudiantes con discapacidad física que no usaban silla de ruedas, de II a I5 años, de cinco escuelas primarias municipales $6^{\circ}$ a $9^{\circ}$ grado de Santarém-Pará. Para la recolección de datos fue utilizada una entrevista semiestructurada. Para el análisis de datos se utilizó la técnica del Discurso del Sujeto Colectivo. Los resultados mostraron que los participantes reconocen y comprenden sus HS y de sus compañeros, concluyen que sus compañeros tienen actitudes de discriminación y exclusión por su condición física. Sin embargo, perciben que las HS están presentes en las clases de Educación Física y favorecen la inclusión.

Palabras-clave: Habilidades sociales. Discapacidad física. Educación Física.

\section{Deficiência física: habilidades sociais e inclusão}

Ser deficiente nas sociedades primitivas antigas e, em alguns momentos do período medieval, era ter um destino trágico, predestinado à morte, à marginalização e à exclusão, sem direito à própria vida. Nessas sociedades, pessoas que nasciam com deficiência ou algum problema aparente, eram abandonadas à própria sorte, castigadas ou até mesmo, isoladas, pois estas sociedades acreditavam que essas pessoas poderiam prejudicar a segurança das demais na tarefa de defender o clã e a tribo dos animais selvagens e/ou transmitir alguma peste, disseminando o pecado (SOUZA, 20I4; SILVA, I987).

Após este período de incivilidade e falta de conhecimento, a partir do lluminismo, marcado pela evolução da ciência, um novo olhar com relação à pessoa com deficiência foi construído. Esta passou a ser vista como portadora de doenças e invalidez. Ressalta-se que hoje o termo correto designado para esses sujeitos é "pessoa com deficiência" ou "educandos com deficiência". Esses termos são defendidos e utilizados na Declaração de Salamanca e Linha de ação sobre necessidades educativas especiais (BRASIL, 1994), na Lei de Diretrizes e Bases da Educação Nacional nº 9394 (BRASIL, 1996) e no Estatuto da Pessoa com Deficiência (BRASIL, 20I5).

O século XIX foi marcado pelo desenvolvimento capitalista, trazendo consigo uma nova visão sobre a pessoa com deficiência, que passou a ser vista como um ser individual e produtivo. É a partir desse entendimento que surge a educação profissional, com intuito de preparar mão de obra suficiente para o progresso capitalista-industrial, assim, aparecem as primeiras intenções do setor público para assistência da educação das pessoas com deficiência (ARANHA, 1995).

No campo da educação especial e Educação Física adaptada, algumas ações políticas foram desenvolvidas e aprimoradas para ampliar o atendimento de crianças com deficiência, como a criação da Secretaria de Educação Especial, a constituição do Comitê Nacional de Ação Conjunta na elaboração de políticas públicas de integração, a Constituição Federal de 1988 e a Lei de Diretrizes e Bases de Educação - LDB/I996. No início de seu percurso histórico, a Educação Física voltada para pessoas com deficiência perpassou por guerras, tendo cunho de reabilitação e o objetivo de reintegração na sociedade. Nos dias atuais, esta deixou de ter cunho especificamente de reabilitação para adentrar também o contexto escolar da educação inclusiva.

Os autores Seabra Junior (2012), Aguiar e Duarte (2005), Gorgatti (2005), Souza (20I I), Meller e Tesche (2007) e Ferreira e Barreto (201I) ressaltam a importância da participação de alunos com deficiência física nas aulas de Educação Física, pois não está direcionada somente à inclusão, mas aos 
benefícios que esta pode oferecer para suas relações sociais e ao desenvolvimento cognitivo-afetivo, resultando em melhor compreensão de sua identidade enquanto ser que se movimenta e possui inúmeras capacidades motoras e habilidades sociais. Segundo Ferreira e Barreto (201 I), a Educação Física que prioriza a inclusão deve direcionar suas práticas corporais para o respeito às diferenças, o reconhecimento da individualidade e da subjetividade e a valorização das relações interpessoais.

O processo de inclusão permitiu a interação social e o desenvolvimento das relações interpessoais. O campo das relações interpessoais é abordado aqui através das habilidades sociais, uma área da psicologia que se preocupa com as interações sociais e com os desempenhos comportamentais eficazes, que consequentemente contribuem para o sucesso individual e coletivo.

As habilidades sociais são um complexo de classes e subclasses que favorecem o desenvolvimento das relações sociais dos sujeitos e têm como objetivo a convivência satisfatória entre os pares de cada ambiente, ou seja, essas habilidades devem estar em consonância com os contextos sociais e culturais nos quais os sujeitos estão inseridos. Os estudos que apoiam teoricamente as habilidades sociais são referenciados por Del Prette e Del Prette (1999, 200I, 2017), Bolsoni-Silva (2002), Greshan (2013), Fumo et al. (2009), entre outros.

E é nesse sentido que psicólogos dessa área confirmam que o desenvolvimento das habilidades sociais de comunicação, civilidade, fazer e manter amizade, empatia, ser assertivo, expressar solidariedade, manejar conflitos e resolver problemas interpessoais, expressar afeto e intimidade, coordenar grupo e falar em público pode contribuir para o desenvolvimento humano, acadêmico e interpessoal dos alunos no contexto da inclusão (DEL PRETTE; DEL PRETTE, 2017; BOLSONI-SILVA, 2002; FUMO et al., 2009; CABALLO; IRURTIA; SALAZAR, 20I3). O desenvolvimento das habilidades sociais perpassa por tomadas de atitudes que influenciam as ações mais conscientes que guiam a prática e os comportamentos humanos, essas ações conscientes são compreendidas como cognições.

As cognições, processo que integra o desenvolvimento humano, são compreendidas como a forma de aquisição de conhecimento. São, ainda, relevantes para a mudança de realidades, ou seja, é a partir das cognições que acontecem as transformações de comportamentos e atitudes, pois se entende que as cognições guiam as ações e as condutas. Os estudos sobre a cognição vêm sendo abordados por Bandura (I996 apud OLAZ, 20I3), Marturana (200I), Pinto (200I) e Vigotsky (200I), os quais a compreendem como o ato de conhecer ou a maneira como se articula o pensamento a partir das ações e das relações estabelecidas com o que se quer conhecer. Garrido, Azevedo e Palma (201 I), Pajares (1992) e Ribas Júnior (2002) estudam a cognição a partir de uma perspectiva ampla, de significar as ideias, os pensamentos, as crenças, as opiniões, os julgamentos, as concepções e as percepções sobre algo ou sobre si mesmo.

É a partir da compreensão dos contextos e dos conceitos envolvidos nesta pesquisa que se fundamenta a problemática a ser investigada: quais as cognições de alunos com deficiência física sobre suas habilidades sociais? O sujeito da pesquisa é o aluno com deficiência física, e o seu ambiente de 
interação social é o espaço das aulas de Educação Física. Portanto, buscou-se como objetivo desta pesquisa conhecer as cognições (crenças, pensamentos, percepções etc.) dos alunos com deficiência física que estão inclusos nas aulas de Educação Física sobre suas habilidades sociais e de seus colegas.

Este artigo trata de uma investigação de cunho educacional, psicológico e de valorização das habilidades sociais no contexto inclusivo, além de priorizar o pensamento do aluno com deficiência, pois acredita-se que a cognição destes poderá ser um instrumento de reflexão deles próprios e do professor que conduz as relações sociais no contexto educacional.

\title{
O caminho da pesquisa
}

Esta pesquisa se fundamenta na abordagem qualitativa de cunho exploratório e descritivo, pois, segundo Santos Filho (2009), o pesquisador se utilizará desse tipo de pesquisa quando objetivar compreender e interpretar o fenômeno, sendo possível explicitá-lo com clareza e profundidade. Godoy (1995, p. 63) explica sucintamente a relação existente entre a pesquisa descritiva e a exploratória:

\begin{abstract}
Quando estamos lidando com problemas pouco conhecidos e a pesquisa é de cunho exploratório, este tipo de investigação parece ser o mais adequado. Quando o estudo é de caráter descritivo e o que se busca é o entendimento do fenômeno como um todo, na sua complexidade, é possível que uma análise qualitativa seja a mais indicada.
\end{abstract}

Desta forma, esta é uma pesquisa de campo realizada na cidade de Santarém, que fica localizada no oeste do estado do Pará. Os lócus da pesquisa foram 5 (cinco) escolas públicas municipais. Para a coleta de dados, solicitou-se à Secretaria de Educação do Município de Santarém - SEMED autorização para realização da pesquisa no ambiente escolar. Foram feitas visitas às escolas indicadas pela SEMED a fim de verificar o quantitativo de alunos que iriam participar. Os professores da disciplina informaram quantos participavam ativamente das aulas. Também foi realizada uma conversa informal com os participantes para uma aproximação pesquisador-participante. Foram marcados os encontros para realização das entrevistas, e o local para realização da pesquisa foi indicado pelos próprios participantes.

Participaram desta pesquisa 5 (cinco) alunos matriculados em escolas públicas municipais, cursando do $6^{\circ}$ ao $9^{\circ}$ ano, entre 11 e 15 anos de idade, inclusos na disciplina de Educação Física. Os alunos investigados foram os designados pela nomenclatura "pessoas com deficiência física não cadeirantes". Este estudo foi submetido ao comitê de ética da Universidade do Estado do Pará, tendo como Certificado de Apresentação de Apreciação Ética o de número 84021618.0.0000.5168, e seguiu todos os princípios éticos previstos na Resolução $n^{\circ} 510 / 16$. Após avaliação e aprovação, foi iniciada a coleta de dados.

A coleta de dados foi realizada através de entrevistas elaboradas com base na técnica "histórias para completar", de Madeleine Backes-Thomas, em que o entrevistador sugere uma situação fictícia, dentro do contexto em que se quer pesquisar, e os entrevistados adentram a história e contam, a 
partir das perguntas, como a situação fictícia acontece no seu cotidiano (BACKES-THOMAS, 1937 apud SCHOENFELDT, 1979). As histórias desta pesquisa tinham como espaço as aulas de Educação Física e consistiam em situações fictícias que implicitamente correspondiam a cada habilidade social proposta por Del Prette e Del Prette (20I7).

Para análise de dados, foi utilizada a técnica de Lefèvre e Lefèvre (2003), o Discurso do Sujeito Coletivo - DSC. Essa proposta é constituída pelas expressões-chave: ideais centrais e ancoragem. As expressões-chave são identificadas no discurso verbal como a essência das respostas dos indivíduos. A ancoragem é o próximo passo metodológico que corresponde ao resultado de algumas expressõeschave de inúmeras ideias centrais. Portanto, esta técnica possibilitou emergir as verbalizações dos participantes a respeito de suas habilidades sociais através de discursos individuais. Interpretou-se o discurso da coletividade, tornando-se importante para compreensão de conteúdos significativos a respeito das cognições dos sujeitos da pesquisa.

\section{Reflexões sobre as habilidades sociais dos alunos com deficiência física no contexto da Educação Física}

Para compreender e analisar as cognições dos alunos com deficiência física sobre a habilidade social de comunicação, lançou-se a seguinte situação: em um outro dia a professora de Educação Física propôs a turma um jogo de vôlei, todos formaram suas equipes e você ainda não havia chegado na quadra. Você percebeu que a atividade daquele dia era a que você mais gostava, no entanto, não tinha nenhuma equipe. Como você faria para entrar em alguma equipe?

Dessa situação, geraram-se três ideias centrais: elaborar estratégias para participar (DSC-A); recorrer ao professor para participar (DSC-B); não participar (DSC-C). Consequentemente, três discursos foram identificados, nos quais dois expressam a habilidade de se comunicar com os colegas e com os professores e um expressa a dificuldade de se comunicar, fazendo com que o sujeito opte em não participar da atividade.

Para constituição do DSC-A, os critérios utilizados para a inclusão das expressões-chave em ideias centrais foram respostas nas quais os sujeitos referenciaram estratégias para participar da atividade:

Então poderia chamar alguns colegas e formar minha equipe. Ou pedia para um colega sair um pouco (Suj: M, K).

O DSC-A, "Elaborar estratégias para participar", traz as expressões em que os alunos com deficiência física dividem a mesma opinião de que a participação em alguma atividade de que mais gosta necessita de elaborar estratégias para se incluir em alguma equipe.

Observa-se que a habilidade de comunicação está presente no comportamento social desses alunos para alcançar o objetivo de participar da atividade, pois o discurso evidencia que os alunos com 
deficiência resolveram esse problema buscando comunicar-se diretamente com os colegas. A pesquisa de Angélico (2004) também revela que a habilidade social de comunicação é bastante evidente em crianças com necessidades educacionais especiais, principalmente em contextos que demandam a utilização dessa habilidade, como no caso de atividades recreativas de jogos e danças. Quiterio e Nunes (2017) veem as habilidades sociais de comunicação como uma ferramenta necessária para estreitar a interação social, pois acreditam que ela pode contribuir para o processo de inclusão.

De acordo com Caballo, Irurtia e Salazar (20I3), os comportamentos são influenciados pelos padrões de atuação e pelos próprios objetivos almejados. Nesse discurso fica claro que o objetivo maior é participar da atividade que mais gosta, o voleibol, assim, o sujeito direciona sua ação a alcançar esse objetivo quando expressa com facilidade a possibilidade de se comunicar para estabelecer uma interação com o outro, demonstrando sua habilidade social de comunicação.

O DSC-B foi construído da seguinte maneira:

Eu falaria com a professora e ela veria alguma possibilidade de me encaixar. Senão eu fico fora (Suj: A2, D).

Esse discurso surge da ideia central "recorrer ao professor" e esclarece que, nesse caso, seguir padrões de atuação seria o mais correto, que ao recorrer ao intermediador (professor) o sujeito teria a garantia da participação na atividade. $O$ discurso também explicita que a comunicação entre o intermediador (professor) e o sujeito (aluno com deficiência física) pode ser estabelecida para a possível participação na atividade. No entanto, quando expressa "Senão eu fico fora", permite entender que, se o intermediador não estabelecer estratégias para a participação do sujeito, este se exclui da atividade de que mais gosta. Dessa forma, o objetivo de participar não foi alcançado e a habilidade de se comunicar ainda está deficitária.

A partir desse discurso, pode-se perceber a influência que o professor exerce sobre o processo de inclusão desses alunos. Professores com fluência de habilidades sociais educativas possuem uma atitude perspicaz em perceber as necessidades de alunos com déficits no desempenho de habilidades sociais e, a partir disso, podem realizar um trabalho pedagógico que vá favorecer uma melhor interação desses alunos nas atividades escolares e, consequentemente, contribuir para inclusão de seus alunos (ROSIN-PINOLA; DEL PRETTE, 20I4).

O DSC-C, em que as expressões-chave foram construídas pela ideia central "Não participo", apresenta-se da seguinte forma:

Eu não ia entrar ia ficar sentada olhando. É! Eu venho às vezes, eu participo, não participo assim com as pessoas (Suj: $\mathrm{Al}$ ).

Nesse discurso, pode-se perceber que o sujeito não possui habilidade em se comunicar e que essa falta pode the proporcionar um isolamento, realizar atividades sozinho sem interação com os 
colegas, além disso, pode-se inferir que a falta dessa habilidade pode proporcionar dificuldades no seu desenvolvimento (DEL PRETTE; DEL PRETTE, 20I4).

Del Prette e Del Prette (20I2), em seu Sistema Multimídia de Habilidades Sociais de Crianças - SMHSC, esclarecem que as falhas nos desempenhos em habilidade sociais podem ser ocasionadas por vários fatores, um deles é a deficiência física, sensorial e mental, em razão da qual os sujeitos podem apresentar condutas passivas, em que demonstram uma postura inerte ou indiferente, buscando isolar-se, omitir-se, autodepreciar-se, submeter-se, aceitar, calar, se excluir, entre outras (GRESHAN, 2013; DEL PRETTE; DEL PRETTE, 2017).

A segunda situação fictícia está relacionada à reflexão sobre a assertividade dos sujeitos, em que a pergunta tem como objetivo levar o sujeito a refletir sobre sua atitude e de seus colegas: em uma atividade de queimada ou mata-no-meio, um colega de sua equipe foi queimado. Segundo a regra do jogo, ele tem que ir para o campo dos queimados, mas, percebendo que você tem dificuldade de se movimentar, o colega pede para você substituí-lo no campo dos queimados. O que você pensa sobre a atitude de seu colega e como você agiria?

Desse questionamento geraram-se três discursos, que foram elaborados pelas ideias centrais: "acredita na solidariedade do outro" (DSC-A); "pensamento de incapacidade e exclusão" (DSC-B); "procura demonstrar que é capaz" (DSC-C). Nos três discursos são evidenciadas as cognições dos sujeitos sobre as questões de exclusão e de poder impor suas opiniões nas situações em que eles estão presentes e vivenciam.

No DSC-A a ideia central retirada foi "acredita na solidariedade do outro":

Eu acho que ele foi solidário. Acho que alguma prevenção para mim não se machucar (Suj: M, D).

Esse discurso expressa que os sujeitos acreditam que o ato de substituição é por questão de cuidado com o outro que tem dificuldade de se locomover. Mas o DSC-B vem contrapor esse pensamento, pois foi constituído pela ideia central "pensamento de incapacidade e exclusão" quando expressa que:

Eu penso que ele tipo estava com pena porque o cara não sabe jogar. Não agiria da mesma forma com o meu colega. Porque eles pensam que eu não consigo e tal. É porque eu sou diferente! Eu acho errado porque ele tá demonstrando que acha que eu não seria capaz. Acontece mais de eles não deixarem eu jogar por esse motivo (Suj: M, AI, A2, D).

Nesse discurso os alunos com deficiência física expressam que acreditam que "É porque eu sou diferente!... Acha que eu não seria capaz", que são isolados ou até mesmo subestimados em suas capacidades no momento da atividade em equipe. $O$ discurso acima revela que essas atitudes são tomadas no contexto das aulas de Educação Física desses sujeitos, o que de certa maneira provoca reflexão para os que atuam nessa área. Souza (2014) corrobora essa proposição, pois este revela a 
necessidade de uma melhor formação acadêmica desses profissionais para o viés da inclusão e para o entendimento das habilidades sociais educativas pró-inclusivas.

Nas atividades das aulas de Educação Física e esportivas se faz necessário incentivar e motivar relações de respeito, valorizando e respeitando as características físicas e os desempenhos próprios e dos colegas, assim como compreender as diferenças e não agir de forma excludente e discriminadora. Darido e Rodrigues (2008) acreditam que a valorização de tais aspectos é fundamental para a formação humana e para evitar situações segregadoras e de exclusão.

O DSC-C, constituído pela ideia central "eu consigo", expressa a crença sobre sua capacidade assertiva de participar e saber se posicionar nas atividades e nas relações entre os colegas. É a partir desse discurso que se pode analisar a habilidade social de assertividade:

Eu sempre mostro que eu consigo. Ficaria no campo, não trocaria com ele. Eu não trocaria! Porque eu não tinha sido queimado! Ou eu poderia até trocar, mas eu iria impor minha opinião sobre isso. Na verdade, eu não sei se trocaria, porque eu gosto de jogar. Porque cada um tem o direito de participar (Suj: M, K, A2, D).

Segundo Del Prette e Del Prette (20I2), a assertividade é uma habilidade em que o sujeito tem a capacidade de expressar sentimentos negativos ou de desagrados, de falar sobre as suas qualidades e defeitos, costuma se posicionar impondo suas opiniões, pode fazer ou recusar pedidos e defender os próprios direitos. O uso da assertividade fica evidente quando os sujeitos expressam "Porque cada um tem o direito de participar", assim, usando do direito de participar e da regra do jogo recusam a substituição solicitada pelo colega e, consequentemente, demonstram que conseguem ser assertivos e por isso “não trocaria com ele. Eu não trocaria! Porque eu não tinha sido queimado!".

Ser assertivo compreende ter ações coerentes em situações de conflito de opiniões ou de interesses, que priorizem os próprios direitos e não restrinjam os direitos dos outros, exigindo, assim, comportamentos de autocontrole para obter um resultado positivo. $\mathrm{Na}$ inter-relação no discurso acima percebe-se que os sujeitos expressam seu potencial positivo em ser assertivo (BOLSONI-SILVA, 2002; BOLSONI-SILVA; MARTURANO, 2002; CABALLO; IRURTIA; SALAZAR, 20I3; FUMO et al. 2009; DEL PRETTE; DEL PRETTE, 2017).

A habilidade social da classe de assertividade também é um fator preponderante para que haja inclusão, entretanto, os professores de alunos com necessidade especiais não dão o devido valor para a habilidade de assertividade e de enfrentamento (AMARO, 20I2). Percebe-se a influência que o docente tem sobre os comportamentos emitidos pelos alunos e, portanto, fica evidente a necessidade de incentivar os docentes a uma intervenção planejada e intencional referente às habilidades sociais educativas que promovam a valorização de comportamentos assertivos e favoreçam a inclusão desses alunos.

Para analisar e compreender como os alunos com deficiência física agem diante das situações que exigem deles a habilidade de civilidade, lançou-se a seguinte situação fictícia: um grupo de amigos 
estava jogando pega-varetas e um dos seus colegas passou pegando o jogo sem pedir aos que estavam usando. Se fosse você que quisesse o brinquedo, como agiria?

Essa situação gerou o seguinte discurso da ideia central "eu pediria”:

Bom se fosse eu, eu ia lá e falaria se eu poderia pegar ou não? Eu ia pedir e esperaria terminar, porque devemos respeitar também os outros que estavam jogando. Então pediria para poder eu jogar com outra pessoa (Suj: M, K, AI, A2, D).

A habilidade social de civilidade é entendida como a habilidade de usar as locuções de regras de ouro como: por favor, obrigado, desculpa, com licença. Além dessas atitudes, também fazem parte dessa habilidade saber aguardar a vez, fazer perguntas e responder, seguir regras ou instruções etc. Dessa maneira, observa-se que no discurso do sujeito coletivo acima os sujeitos participantes possuem a habilidade de civilidade para a situação em questão, pois expressam claramente que poderiam “respeitar também os outros que estavam jogando" para assim poder participar da atividade.

A habilidade social de civilidade também é bastante utilizada por crianças com síndrome de Down, principalmente nos contextos de sala de aula (ANGÉLICO, 2004). Amaro (20I2) averiguou que ao comparar as dez habilidades sociais mais valorizadas e menos valorizadas por docentes que atuam com crianças com necessidades especiais, a HS de civilidade mostrou-se ser de maior relevância.

O desenvolvimento de habilidades sociais eleva as relações pessoais a níveis de satisfação mútua, pois fica claro que muitas atitudes, comportamentos e ações têm relação com a cognição e as habilidades sociais. Portanto, infere-se que as HS são reflexos dos pensamentos sobre as situações conflitantes vivenciadas pelos sujeitos (CABALLO; IRURTIA; SALAZAR, 20I3).

Para averiguar a habilidade social de fazer e manter amizade, foi elaborada a seguinte situação: uma das atividades das aulas de Educação Física propostas pela professora é o seminário sobre capacidades físicas. Você e sua equipe ficaram com o tema "força". Um de seus colegas adora falar na frente e não sente nenhuma dificuldade para isso. Mas sua melhor amiga apresentou dificuldade e ele sentiu que ela estava com problemas para continuar falando e quis ajudá-la. Assim que ela parou de falar, ele buscou reforçar o que ela tinha esquecido de explicar. O que você pensa sobre isso?

Dessa situação formou-se um discurso a partir das expressões-chave "atitude muito boa", "é bom ajudar" e "é um trabalho em equipe”. Conforme o discurso a seguir:

Eu acho interessante essa atitude que aconteceu. Isso foi bem bacana e eu faria o mesmo como eu fiz com o meu colega. Por respeito, porque ela tinha dificuldade e eu ajudaria ela. Eu complementei a informação dela, mas sem desmerecer o que ele tinha falado. É bom a gente ajudar quando pode e quando já sabe alguma coisa e quando às vezes a gente vê uma pessoa com dificuldade a gente vai e ajuda. $\bigcirc$ meu colega, ele ajuda sempre, quando a gente vai apresentar trabalho, se a gente não sabe ou se esquece, ele vai lá explicar, porque ele já estudou tudo. É bom ele ajudar a gente. Eu faria a mesma coisa, pois é uma atitude boa.

Eu acho bom isso, afinal é um trabalho em equipe. É um trabalho em grupo e eu acho que isso é importante (Suj: M, AI, A2, K, D). 
Esse discurso revela que os alunos com deficiência física demonstram ter sentimento de empatia. Infere-se que esse sentimento pode favorecer e fortalecer as relações de amizade. A habilidade de fazer amizade está relacionada a atitudes como oferecer ajuda e cooperar, mais amplamente está relacionada à postura de se enturmar, ou seja, relacionar-se com grupos ou equipes que correspondem ao seu nível de idade, de escolhas e atitudes da mesma cultura (DEL PRETTE; DEL PRETTE, 20I2), como esclarece o trecho: “É bom a gente ajudar quando pode e quando já sabe alguma coisa e quando às vezes a gente vê uma pessoa com dificuldade a gente vai e ajuda [...] É um trabalho em grupo e eu acho que isso é importante". Entende-se que a cognição dos alunos com deficiência física sobre fortalecer amizade estimula uma convivência harmoniosa entre os grupos facilitando assim a interação social desses alunos.

Outra habilidade social que foi explorada na entrevista diz respeito à capacidade de expressar solidariedade, habilidade que também é considerada como facilitadora e mantenedora de amizade. Essa HS é entendida como a maneira como o sujeito expressa o seu sentimento de cooperação com as pessoas que estão próximas e que necessitam de ajuda. Para essa análise, lançou-se o seguinte questionamento: em um outro dia de atividades práticas nas aulas de Educação Física, o conteúdo do dia é futsal, mas você não tem muita habilidade nesse esporte, mesmo porque você tem dificuldade de se locomover. No entanto, seu melhor amigo lhe incentiva a participar e diz que estará do seu lado e vai Ihe ajudar nas bolas difíceis. $O$ que você pensa sobre a atitude de seu amigo?

Desse questionamento surge o seguinte DSC-A:

Eles falam que eu sou melhor goleiro lá e tal. E aí eu fico me achando lá na hora, eu não deixo entrar nenhum gol. $\mathrm{E}$ eu acho interessante, assim bem legal mesmo. Eu penso que ele quer me ajudar é bom. Eu penso que é uma atitude sensata ele querer ajudar, e outras pessoas também deveriam ser assim, pois é bom incentivar as pessoas. Dá um apoio (Suj: AI, A2, M, K, D).

Nesse discurso, percebem-se duas cognições expressas nas ideias centrais: "que ajudar é considerado uma boa atitude a fazer" e "que outras pessoas poderiam agir dessa maneira". A pretensão do questionamento era identificar no discurso o valor que os alunos com deficiência física atribuem a ser solidário, dessa forma, verbalizaram que "é bom, eu penso que é uma atitude sensata ele querer ajudar" e que acreditam que essa atitude deveria ser reproduzida por outras pessoas, assim, ser solidário deveria ser uma atitude a ser multiplicada. No entanto, surgiu outro discurso (DSC- B), que revela questões de preconceito:

Porque tem alguns alunos que não gostam, que tipo, pessoas como eu participe, por achar que vai atrasar o jogo ou vai ocorrer alguma mudança. Não deveria ter tanto preconceito sobre isso (suj: $\mathrm{M}, \mathrm{Al}$ ).

Não se esperava que surgissem verbalizações que revelassem sentimento sobre a exclusão e o preconceito: “Não deveria ter tanto preconceito sobre isso". Dessa maneira, não se pode deixar 
alheia da análise essa cognição. $\bigcirc$ trecho desse discurso revela o quanto ainda está presente o preconceito e a exclusão, assim como a valorização da competição, do ganhar e perder. Analisando sob a abordagem das habilidades sociais, percebe-se que os colegas não demonstram respeito às diferenças e não compreendem a situação em que se encontra o colega com deficiência física.

A inclusão está relacionada ao ato de participar junto com os alunos sem distinção. As percepções dos alunos com deficiência sobre a inclusão é que não se sentem incluídos, e, ao mesmo tempo, expressam um sentimento de inferioridade pelo olhar dos outros colegas (ALVES, 20I3). Portanto, pode-se inferir que, para os alunos com deficiência física, a exclusão ainda é perceptível no contexto escolar e nas atividades das aulas de Educação Física.

Ainda sobre a cognição do aluno com deficiência física a respeito das suas habilidades sociais e de seus colegas, a seguinte situação fictícia foi lançada para analisar e compreender como estes percebem a empatia em seus colegas: vocês estão todos correndo na aula de Educação Física e você de repente cai. $O$ que seus colegas costumam fazer e como você gostaria que seus colegas fizessem? A empatia é uma habilidade social que envolve, segundo Del Prette e Del Prette (20I2), atitudes que demonstram interesse pelo outro, expressar compreensão pelo sentimento do outro, expressar respeito às diferenças, além de compartilhar e oferecer ajuda. Alguns desses sentimentos são evidenciados nos discursos emergidos pelos participantes:

Primeiro eles riem, ficam rindo ou olhando. E eu também fico rindo de mim mesmo quando eu caio e depois eles me ajudam a levantar. E também a maioria das pessoas quando a gente cai eles começam a rir. Já aconteceu isso, muitos deles me ajudam, chamam a professora, ela também me ajuda. Se fosse com o meu colega, eu ia ajudar (Suj: M, AI, A2, K, D).

$\mathrm{Na}$ formação do discurso a ideia central encontrada nas palavras-chave foi "riem, mas me ajudam". Esse trecho caracteriza que, por estarem na fase da adolescência, algumas situações são inerentes aos grupos de amigos. Essas situações devem ser levadas em consideração, pois, segundo Bolsoni-Silva (2002) e Bolsoni-Silva e Marturano (2002), as dimensões situacionais, culturais e pessoais influenciam o repertório de habilidades sociais. Nesse discurso fica expresso que a dimensão situacional está relacionada à maneira como os colegas podem se comportar perante o acontecido, o que acaba sendo uma conduta permitida nos grupos de adolescentes. Sendo assim, apesar de rirem da situação, os colegas estão sempre dispostos a ajudar, o que é explicitado quando verbalizam que "Já aconteceu isso, muitos deles me ajudam, chamam a professora, ela também me ajuda”.

Outro trecho do discurso que chama atenção é quando os sujeitos afirmam que, "Se fosse com o meu colega, eu ia ajudar”. Essa fala evidencia um desempenho social desejável. Este é caracterizado como a maneira como o sujeito pensa ou age sobre as situações que requerem tarefas interpessoais. Portanto, o manejo de uma tarefa interpessoal é influenciado pelo repertório de habilidades sociais que o sujeito possui (DEL PRETTE; DEL PRETTE, 20I7). Isso implica afirmar que as 
cognições, que são um produto da interação social, influenciam as ações e os comportamentos dos sujeitos. Logo, compreende-se que os pensamentos e as ações dos alunos com deficiência física em análise se constituem por um repertório desejável de habilidades sociais a respeito da empatia (RIBAS JÚNIOR, 2002).

A respeito da habilidade social "expressar afeto e intimidade", a situação fictícia proposta foi: em uma dinâmica sobre amizade, a professora pede para todos escolherem um colega e através de um desenho falar sobre ele. $O$ que você pensa sobre essa atividade e como você expressaria sua amizade por alguém. Desta, emergiram os seguintes discursos.

DSC-A:

É uma atividade que até minha professora poderia praticar com a gente. Acho interessante é porque a pessoa pode se expressar do jeito que ela é. Mas eu ia juntar todos os meus colegas e formar só um desenho de todos. Colocava as qualidades e os defeitos. É bom saber o que as pessoas não gostam em você. Tipo se tu estás agindo de uma forma errada. É bom tu saber o porquê. Falaria sobre ela, sobre a pessoa, sobre as qualidades dela. Iria relembrar tudo o que ela fez por mim. Eu falava palavras de gratidão (Suj: AI, A2, M, D, K).

DSC-B:

É uma atividade para falar do meu amigo, eu tenho dificuldade. Não me sinto à vontade para fazer isso, porque às vezes eles fazem deboche na frente. Mas falaria as qualidades dele, mas não falaria dos defeitos (Suj: K, D).

No DSC-A, as ideias centrais identificadas foram: "expressar do jeito que ela é" e "falava palavras de gratidão". Nessas verbalizações pode-se inferir que os alunos com deficiência física conseguem expressar seus sentimentos, assim como revelam que expressar sentimentos, para eles, está relacionado com descrever o que mais e menos gosta no amigo. Quando esclarecem que "É bom saber o que as pessoas não gostam em você", estão suscetíveis a receber críticas e sugestões, como pode-se verificar em: "se tu estás agindo de uma forma errada é bom tu saber o porquê". Portanto, "é uma atividade que até minha professora poderia praticar com a gente", a partir dessa cognição se fez compreender que atividades como essas favorecem o desenvolvimento de habilidades sociais promovendo uma redução de comportamentos antissociais (DEL PRETTE; DEL PRETTE, 20I4), pois os alunos acreditam que esse tipo de atividade gera sentimentos de "gratidão" e, consequentemente, subtende-se que fortalece os laços de amizade.

Já no DSC-B verifica-se que, para alguns sujeitos, falar do amigo é uma tarefa que não os deixa à vontade, revelando que "É uma atividade [..], eu tenho dificuldade". Em sua cognição, essa é uma atividade que pode ser conflituosa e que, nesse caso, o melhor é expressar "as qualidades dele" e "não falaria dos defeitos". Essa situação, segundo Del Prette e Del Prette (2002) e Greshan (2013), é compreendida como reações não-habilidosas passivas, ou seja, atitudes que os sujeitos podem apresentar quando em situações de interação social de enfrentamento, e resulta em comprometimento 
da competência social, havendo reações de forma passiva por meio de fugas ou de incômodo e ações de comportamento internalizante (isolamento, ansiedade, angústia etc.).

Outra HS averiguada foi "coordenar grupo", que está relacionada à capacidade de desempenhar comportamentos de liderança e atitudes coerentes em momentos de conflito de interesses, que visem o objetivo do grupo com quem se interage (DEL PRETTE; DEL PRETTE, 2017). Dessa forma, para compreender as cognições dos alunos com deficiência física a respeito do desempenho social de coordenação de grupos, lançou-se o seguinte questionamento: a professora propôs à sua turma uma atividade de grupo, mas disse que cada um no grupo teria uma tarefa a cumprir. Essa atividade era de pesquisa sobre jogos e brincadeiras antigas. E cada grupo deveria ter um líder para distribuir e cobrar as tarefas do restante do grupo. Você pensa que poderia ser o líder do seu grupo? Desse questionamento emergiu o seguinte discurso a ser analisado:

É assim, eu sou o único que sou mais dedicado na minha sala. Então sempre que tem atividade em grupo eu sempre sou líder. Às vezes eu sou, ou às vezes são os meus colegas. Pediria para abrir uma roda e eu distribuiria entre eles a tarefa a quem fosse e quem se adequasse na atividade, e eu distribuiria as tarefas. Eu divido por partes, pergunto $\circ$ que eles querem fazer primeiro, então eu divido, através de igualdade para cada um ficar com uma parte, para ninguém se cansar e nem fazer de mais. Eu ia explicar como fazer e ajudar também (Suj: M, AI, A2, K, D).

Nesse discurso fica evidente que os alunos aqui questionados conseguem lidar facilmente com a demanda social requerida para desempenhar a liderança de grupo no contexto escolar, esclarecido nesta verbalização: "Então sempre que tem atividade em grupo eu sempre sou líder". Para além do desempenho de ser liderança de equipe, os alunos questionados também expressam a forma de conduzir a atividade diante da demanda solicitada: "Pediria para abrir uma roda e eu distribuiria entre eles a tarefa a quem fosse e a quem se adequasse na atividade, e eu distribuiria as tarefas". Essas atitudes condizem com reações habilidosas, que são consideradas comportamentos que viabilizam a competência social, ou seja, que facilitam que a pessoa enfrente situações difíceis demandadas no seu ambiente de interação (DEL PRETTE; DEL PRETTE, 20I4; MARTURANO; LOUREIRO, 20I4).

Em complementação, sugeriu-se ao público outro questionamento, que visa analisar a habilidade social de falar em público: no retorno da atividade de pesquisa, a professora pede ao líder do grupo, que é você, para apresentar o trabalho na frente de todos da turma. O que você acha sobre isso?

Essa situação fictícia revelou dois discursos que emergiram das ideias centrais: DSC-A, "eu não consigo falar na frente", e DSC-B, "eu gosto de explicar".

DSC-A:

Bom eu acho que seria uma atitude errada dela só para eu apresentar, já que todos fizemos por que não todo mundo apresentar? Eu acho meio injusto, porque como foi divido entre todos do grupo. Eu ia, mas eu ia ficar mais nervosa, o meu coração ficaria batendo muito forte. Não gosto muito de falar na frente, eu sou tímida, às 
vezes dá um branco e às vezes eu esqueço. Mas às vezes eu falo, eu tenho medo de esquecer, mas acho que é normal. Sinto muita vergonha (Suj: AI, A2, K).

DSC- B:

Isso Acontece. Quando vai só eu, eles sempre perdem ponto. Na verdade, eu não gosto de ler muito na frente, eu gosto é de explicar! Eu vou lá na frente e eu explico, não sinto vergonha. Às vezes eu falo na frente. Eu só falo quando eu vou em eventos (Suj: $M, D$ ).

Os discursos acima apresentam um conflito de opiniões, sendo que no DSC-A fica evidente o quanto falar em público é uma demanda de difícil desempenho social para crianças nessa faixa etária, como mostra a verbalização: "Eu ia, mas eu ia ficar mais nervosa, o meu coração ficaria batendo muito forte. Não gosto muito de falar na frente, eu sou tímida, as vezes dá um branco e às vezes eu esqueço". Nessa verbalização, pode-se inferir que o desempenho da habilidade de falar em público e de autocontrole ainda não está amadurecido e que, consequentemente, provoca reações não-habilidosas passivas, como expressada nesta frase: "Sinto muita vergonha". Del Prette e Del Prette (2012) esclarecem que as deficiências podem ser um fator contributivo para falhas na fluência e no desempenho das habilidades sociais

O DSC-B apresenta o inverso, pois os sujeitos verbalizam que conseguem desempenhar a demanda requerida com facilidade, como se pode ver neste trecho: "eu vou lá na frente e eu explico, não sinto vergonha". Assim, a verbalização aponta que os alunos com deficiência física podem ter reações habilidosas para falar em público quando expressam essa facilidade na seguinte verbalização: "Eu só falo quando eu vou em eventos".

Dessa forma, a partir de um entendimento empírico, para os alunos com deficiência física, a condição física não parece implicar no desempenho da habilidade social de se expor ou falar em público, como está exemplificado no SMHSC de Del Prette e Del Prette (2012). No entanto, analisando os discursos DSC-A e DSC-B, pode-se considerar que a cognição dos sujeitos implica diretamente em seu comportamento (OLAZ, 20I3), ou seja, não se pode generalizar que pela condição física estes não desempenham as habilidades sociais de maneira habilidosa ou vice e versa. Portanto, pode-se inferir que o contexto cultural, escolar e familiar também é um fator influenciador no desempenho de comportamentos socialmente aceitáveis.

Para compreender as cognições dos alunos com deficiência física sobre a habilidade social de manejar e resolver situações que envolvam conflitos, a seguinte arguição foi feita: em uma atividade prática de jogo, um de seus colegas empurra o outro e ele cai e se machuca, consequentemente começa uma briga. $O$ que você pensa disso?

Dessa arguição um único discurso foi gerado com base nas ideias centrais "atitude errada" e "ter um diálogo": 
Bom eu acho que a atitude errada, primeiramente, é a do colega que empurrou, pois ele não deveria ter feito isso. Eu poderia ser sem querer ou não! Mas o que eu acho disso, eu acho que não deveria brigar. Mas, conversar e ter um diálogo na hora. Não deveria começar a briga, ele deveria ajudar quem caiu, deveria perguntar se está bem, se estava sentindo bem. Se eu visse uma situação dessa, diria para pararem de brigar e ajudar um ao outro, porque isso não ia levar a lugar nenhum. E se fosse comigo, eu não ia brigar, eu só ia falar tipo, poxa por que você me empurrou. Não é para fazer isso! Porque essas atividades são para gente participar, jogar e não pra ter briga. Porque não gosto de briga. Eu acho que brigar com eles também não adiantaria (Suj: $M, A I, A 2, K, D)$.

A habilidade social de manejar e resolver conflitos interpessoais compreende-se como um processo atitudinal que envolve sistemas comportamentais, cognitivos e afetivos (LEME, 2004). Esse processo exige que as pessoas reconheçam as suas cognições e sentimentos para assim manejar o seu comportamento perante situações que exigem parcimônia. No discurso supracitado fica evidente a cognição dos sujeitos pesquisados, por acreditarem que gerar um conflito é resultado de uma "a atitude errada". Além disso, compreendem que esse tipo de situação pode ser evitado quando se pode "conversar e ter um diálogo na hora".

No entanto, Rodrigues, Dias e Freitas (2010) afirmam que o conflito é inerente ao ser humano, e, assim, é uma manifestação sociocultural que leva aos ajustes das relações sociais. Assim, o conflito pode contribuir para o desenvolvimento de sentimentos de empatia, valorização das diferenças e, consequentemente, provoca um amadurecimento social dos sujeitos. Essa situação é evidenciada quando os alunos com deficiência física expressam que "Não deveria começar a briga, ele deveria ajudar quem caiu, deveria perguntar se está bem e se estava sentindo bem".

O amadurecimento social pode ser percebido quando colocado no discurso como os alunos se comportariam na situação fictícia:

Se eu visse uma situação dessa diria para pararem de brigar e ajudar um ao outro, porque isso não ia levar a lugar nenhum. E se fosse comigo, eu não ia brigar, eu só ia falar tipo, poxa por que você me empurrou. Não é para fazer isso! Porque essas atividades são para gente participar, jogar e não para ter briga.

Portanto, ao que se percebe, a partir das verbalizações, é que os alunos com deficiência física possuem a habilidade de gerenciar conflitos que estes presenciam ou vivem.

\section{Resultados}

Com base nos discursos produzidos a partir das situações fictícias, no contexto das aulas de Educação Física, pôde-se obter resultados relevantes. Infere-se que, a respeito da comunicação, os participantes acreditam que é uma ferramenta necessária para a participação e inclusão, assim como facilita a interação com o outro. Dessa forma, os sujeitos acreditam que o déficit no desempenho da habilidade comunicação contribui para o isolamento nas atividades do cotidiano escolar, incluindo as aulas de Educação Física. 
Acerca da assertividade, as cognições inferidas são de que o público pesquisado tem a capacidade de se posicionar e priorizar-se sem prejudicar o outro perante situações em que seus direitos são violados, ou quando são excluídos. A cognição sobre civilidade que foi expressa indica que os participantes conseguem desempenhar positivamente essa habilidade, pois acreditam que saber esperar e respeitar o outro favorece a interação e a relação social. A respeito da habilidade "fazer e manter amizade", a cognição expressada pelos participantes está relacionada à crença de que, para ser amigo, tem que valorizar, respeitar, ajudar e se colocar no lugar do outro. Consequentemente, ao fortalecer laços de amizade, estão valorizando uma convivência saudável.

Sobre expressar solidariedade, o discurso emergiu a cognição de que é um sentimento de querer ajudar o outro e que essa atitude deve ser multiplicada por outras pessoas. Quanto à habilidade de empatia, os participantes compreendem que é um ato de sempre buscar ajudar o colega e se colocar no lugar do outro. Como resultado da cognição da habilidade "expressar afeto e intimidade", os participantes a compreendem como uma atitude de demonstrar o sentimento de aprovação ou reprovação a respeito do outro. Buscar expressar esses sentimentos fortalece os laços de amizade e de gratidão, mas não é uma tarefa fácil de ser desempenhada. Ao contrário dessa habilidade, na de coordenar grupo, foi evidenciado que os participantes têm facilidade em desempenhar tarefas desse tipo e que essa habilidade é requerida constantemente e, assim, está presente em seu dia a dia e no seu repertório de habilidades.

Já na habilidade de falar em público, obtiveram-se duas cognições, na primeira, os sujeitos expressaram a dificuldade de desempenhar essa habilidade, mas isso não implica não realizar a tarefa. $\mathrm{Na}$ outra cognição, os sujeitos apresentaram que essa habilidade é bastante empolgante e de fácil desempenho. E sobre a habilidade social de manejar conflito, infere-se que os sujeitos compreendem que gerar conflitos é uma atitude negativa e que deve ser evitada ou conduzida de forma a não prejudicar as partes envolvidas.

A cognição sobre as habilidades sociais de seus colegas expressou a forma como seus colegas os percebem no contexto dessa interação social, os participantes compreendem que seus colegas ainda têm atitudes de discriminação e de exclusão por conta de sua condição física. Nesse sentido, é importante compreender que a vivência escolar é de suma importância no desenvolvimento social e educacional para as crianças e adolescentes de nossa cultura. Essas vivências contribuem para fortalecer as relações interpessoais e, consequentemente, para um o sucesso na escolarização, favorecendo o aprendizado e o reconhecimento das regras da sociedade para uma conduta pró-social, assim tendo um posicionamento positivo para as competências sociais da vida adulta (DEL PRETTE; DEL PRETTE, 2003). Portanto, acredita-se que os resultados podem contribuir para a ampliação do conhecimento dos eixos estudados, a cognição, as habilidades sociais e a inclusão no contexto das aulas de Educação Física. 


\section{Considerações Finais}

A presente pesquisa teve como objetivo investigar as cognições de alunos com deficiência física que estão inclusos nas aulas de Educação Física sobre suas habilidades sociais. Para alcançar esse objetivo, a pesquisa teve como norteamento dois objetivos específicos: conhecer o que os alunos com deficiência física pensam a respeito de suas habilidades sociais e de seus colegas e investigar as cognições dos alunos com deficiência física sobre a sua relação interpessoal nas aulas de Educação Física.

Acredita-se ser importante que o educando reflita sobre sua maneira de se relacionar com os seus colegas e perceba que é nessa relação que ele desenvolve os aspectos cognitivos, afetivos e sociais. Ainda, as cognições dos alunos podem levar os professores a refletir sobre sua própria atuação como mediadores das relações e do desenvolvimento das habilidades sociais no espaço das aulas de Educação Física e, assim, melhor conduzir o processo educativo para uma efetiva inclusão e desenvolvimento de habilidades sociais.

Além disso, compreender as cognições desses alunos sobre suas habilidades sociais é um ponto de partida para futuras análises no contexto das habilidades sociais de alunos com deficiência física, pois acredita-se que existe um campo muito amplo para ainda ser explorado. $O$ fato é que muitos estudos ainda são necessários, bem como saber como esse público interpreta e demonstra suas habilidades sociais no contexto escolar. Dessa maneira, verificam-se algumas considerações e aspectos que podem contribuir para o aprimoramento de pesquisas futuras.

A respeito das limitações desta pesquisa, pode-se considerar o número de participantes, encontraram-se poucos que estavam de acordo com os critérios de inclusão. Ao abranger escolas estaduais, maiores seriam as possibilidades de ampliar o número de participantes e consequentemente ampliar as cognições sobre as habilidades sociais. Outra limitação foi a faixa etária selecionada, pois alguns estavam com distorção idade/ano, assim, alguns alunos que estavam no ano escolar requisitado estavam com idade acima do que se pretendia investigar.

As principais contribuições desta pesquisa são: ampliar o campo de investigação e o conhecimento de pesquisas que têm alunos com deficiência física como participantes, principalmente aquelas que têm como foco as cognições sobre as habilidades sociais. Ainda no campo teórico, esta pesquisa tem grande contribuição para aquelas que usam o contexto escolar como um espaço investigativo, em especial, na área da Educação Física escolar, contexto aqui utilizado como ambiente de vivência das habilidades sociais.

Portanto, a partir desta pesquisa, vislumbra-se contribuir para ampliação das discussões que permeiam as habilidades sociais, o aluno com deficiência física e a Educação Física inclusiva, de modo que, ao se perceber a importância desse assunto, seja possível vislumbrar novas cognições e reflexões sobre a atuação docente no contexto das habilidades sociais e da Educação Física inclusiva. 


\section{Referências}

AGUIAR, J. S. de; DUARTE, É. Educação inclusiva: um estudo na área da educação física. Rev. Bras. Ed. Esp., Marília, v. I I, n. 2, p. 223-240, 2005. DOI: https://doi.org/I0.I590/SI4I365382005000200005. Disponível em: http://www.scielo.br/pdf/\%0D/rbee/vl In2/vI In2a5.pdf. Acesso em: 14 jun. 2017.

ALVES, M. L T. O aluno com deficiência visual nas aulas de Educação Física: análise do processo inclusivo. 2013. 77 f. Tese (Doutorado em Educação Física) - Faculdade de Educação Física, Universidade Estadual de Campinas, Campinas, SP, 2013. Disponível em: http://www.repositorio.unicamp.br/handle/REPOSIP/275I07. Acesso em: I4 jun. 2017.

AMARO, L. de C. P. Habilidades sociais relevantes para estudantes com e sem necessidades educacionais especiais segundo a avaliação do professor. $2012.83 \mathrm{f}$. Dissertação (Mestrado em Educação Especial) - Universidade Federal de São Carlos, São Carlos, 2012. Disponível em: https://repositorio.ufscar.br/handle/ufscar/3 I09. Acesso em: I4 jun. 2017.

ANGÉLICO, A. P. Estudos descritivo de habilidades sociais de adolescentes com Síndrome de Down. 2004. 126 f. Dissertação (Mestrado em Educação Especial) - Universidade Federal de São Carlos, São Carlos, 2004. Disponível em: http://bdae.org.br/handle/I23456789//893. Acesso em: I4 jun. 2017.

ARANHA, M. S. F. Integração Social do Deficiente: Análise Conceitual e Metodológica. Temas em Psicologia, Ribeirão Preto, v. 3, n. 2, p. 63-70, ago. 1995. Disponível em: http://pepsic.bvsalud.org/scielo.php?script=sci_arttext\&pid=SI 413-389X1995000200008. Acesso em: I4 jun. 2017.

BOLSONI-SILVA, A. T. Habilidades sociais: breve análise da teoria e da prática à luz da análise do comportamento. Interação em Psicologia, Curitiba, v. 6, n. 2, p. 233-242, dez. 2002. DOI: http://dx.doi.org/ / 0.5380/psi.v6i2.33 I I. Disponível em: https://revistas.ufpr.br/psicologia/article/view/33I I. Acesso em: 03 jun. 202 I.

BOLSONI-SILVA, A. T.; MARTURANO, E. M. Práticas educativas e problemas de comportamento: uma análise à luz das habilidades sociais. Estudos de Psicologia, Natal, v. 7, n. 2, 2002. ISSN I6784669. DOI: https://doi.org// 0.1590/S I4I3-294X2002000200004. Disponível em: https://www.scielo.br/j/epsic/a/9mqzq5FXLBVB6PyZPMDF3LR/abstract/?lang=pt. Acesso em: 3 jun. 2021.

BRASIL. Constituição da República Federativa do Brasil de 1988. Brasília, DF: Presidência da República, [2016]. Disponível em: http://www.planalto.gov.br/ccivil_03/Constituicao/ Constituiçao.htm. Acesso em: I jan. 2017.

BRASIL. Declaração de Salamanca e Linha de Ação sobre Necessidades Educativas Especiais. Brasília: Coordenadoria Nacional para Integração da Pessoa Portadora de Deficiência, 1994. Disponível em: portal.mec.gov.br/seesp/arquivos/pdf/salamanca.pdf. Acesso em: 10 mai. 2017.

BRASIL. Lei de Diretrizes e Bases da Educação Nacional. Diário Oficial [da] República Federativa do Brasil, Poder Legislativo, Brasília, DF, v. 19, p. 26, 1996.

BRASIL. Lei $\mathbf{n}^{\circ}$ 13.I 46, de 06 de julho de 20I5. Estatuto da Pessoa com Deficiência. Brasília: Presidência da República, 2015. Disponível em: http://www.planalto.gov.br/ccivil_03/_ato20152018/20I5/lei/l 3 I46.htm. Acesso em: 10 mai. 2017. 
CABALLO, V. E.; IRURTIA, M. J.; SALAZAR, I. C. Abordagem cognitiva na avaliação e intervenção sobre habilidades sociais. In: DEL PRETTE, A.; DEL PRETTE, Z. A. P. (Org.). Psicologia das habilidades sociais: diversidade teórica e suas implicações. 3. ed. Petrópolis, RJ: Vozes, 2013.

DARIDO, S. C.; RODRIGUES, H. de A. As três dimensões dos conteúdos na prática pedagógica de uma professora de educação física com mestrado: um estudo de caso. Revista da Educação Física/UEM, Maringá, v. 19, n. I, p. 5I-64, 2008. DOI: https://doi.org//0.4025/REVEDUCFIS.VI9II.43 I4. Disponível em: https://periodicos.uem.br/ojs/index.php/RevEducFis/article/view/43 I4. Acesso em: 10 mai. 2017.

DEL PRETTE, A.; DEL PRETTE, Z. A. P. Competência social e habilidades sociais: manual teórico-prático. I. ed. Petrópolis, RJ: Vozes, 2017.

DEL PRETTE, A.; DEL PRETTE, Z. A. P. Habilidades sociais, desenvolvimento e aprendizagem: questões conceituais, avaliação e intervenção. 2. ed. Campinas, SP: Alínea, 2003.

DEL PRETTE, A.; DEL PRETTE, Z. A. P. Psicologia das habilidades sociais: terapia e educação. 9. ed. Petrópolis, RJ. Vozes, 1999.

DEL PRETTE, A.; DEL PRETTE, Z. A. P. Psicologia das relações interpessoais: vivências para o trabalho em grupo. II. Ed. Petrópolis, RJ: Vozes, 200 I.

DEL PRETTE, A.; DEL PRETTE, Z. A. P. Psicologia das Relações Interpessoais: vivências para o Trabalho em Grupo. Petrópolis, RJ: Vozes, 2014.

DEL PRETTE, A.; DEL PRETTE, Z. A. P. Sistema Multimídia de Habilidades Sociais de Crianças: (SMHSC-Del-Prette). I. ed. São Paulo: Casa do Psicólogo, 2012.

FERREIRA, E. L.; BARRETO, M. A. Práticas Corporais Inclusivas. In: FERREIRA, E. L. (Org.). Atividades Físicas Inclusivas para Pessoas com Deficiência. 2. ed. Niterói: Intertexto. 20I I. 4 v. p. 47-57.

FUMO, V. M. S.; MANOLIO, C. L.; BELLO, S.; HAYASHI, M. C. P. I. Produção científica em habilidades sociais: estudo bibliográfico. Rev. Bras. de Ter. Comp. Cogn., Campinas, v. II, n. 2, p. 246-26, 2009. DOI: http://dx.doi.org//0.3 I505/rbtcc.vl Ii2.40I. Disponível em: http://pepsic.bvsalud.org/scielo.php?script=sci_arttext\&pid=SI 5 17-55452009000200005. Acesso em: I0 mai. 2017.

GARRIDO, M. V.; AZEVEDO, C.; PALMA, T. Cognição social: fundamentos, formulações atuais e perspectivas futuras. Psicologia, Lisboa, v. 25, n. I, p. I I3-I57, 20 I I. DOI:

https://doi.org/I0.17575/rpsicol.v25il.282. Disponível em:

https://revista.appsicologia.org/index.php/rpsicologia/article/view/282. Acesso em: 10 mai. 2017.

GODOY, A. S. Introdução à pesquisa qualitativa e suas possibilidades. Rev. Adm. Empres., São Paulo, v. 35, n. 2, mar./abr. 1995. DOI: https://doi.org/I0.I590/S0034-7590I995000200008.

Disponível em: https://www.scielo.br/j/rae/a/wf9CgwXVjpLFVgpwNkCgnnC/?format=pdf\&lang=pt. Acesso em: 10 mai. 2017.

GORGATTI, M. G. Educação física escolar e inclusão: uma análise a partir do desenvolvimento motor e social de adolescentes com deficiência visual e das atitudes dos professores. 2005. Tese (Doutorado em Biodinâmica do Movimento Humano) - Escola de Educação Física e Esporte, Universidade de São Paulo, São Paulo, 2005. DOI: https://doi.org/I 0.I I606/T.39.2005.tde-I8042007I 35446. Disponível em: https://teses.usp.br/teses/disponiveis/39/39|32/tde-18042007-I 35446/ptbr.php. Acesso em: 15 set. 2017. 
GRESHAM, F. M. Análise do comportamento aplicadas as habilidades sociais. In: DEL PRETTE, A.; DEL PRETTE, Z. A. P. (Org.). Psicologia das habilidades sociais: diversidade teórica e suas implicações. 3. ed. Petrópolis, RJ: Vozes, 2013.

LEFÈVRE, F.; LEFÈVRE, A. M. C. Depoimentos e Discurso: uma proposta de analise em pesquisa social. I. ed. Brasília: Liber Livro Editora, 2003.

LEME, M. I. da S. Resolução de conflitos interpessoais: interações entre cognição e afetividade na cultura. Psicologia: Reflexão e Crítica, Porto Alegre, v. I7, n. 3, p. 367-380, 2004. DOI: https://doi.org/I0.1590/s0 I02-797220040003000 I0. Disponível em: https://www.scielo.br/j/prc/a/bXSgybrQjzXxHpNhQfYGMS/?lang=pt\&format=pdf. Acesso em: 15 set. 2017.

MARTURANA, R., H. Cognição, ciência e vida cotidiana. Organização e tradução de Cristina Magro e Victor Paredes. Belo Horizonte: Ed. UFMG, 200I. 203 p.

MARTURANO, E. M.; LOUREIRO, S. R. O desenvolvimento socioemocional e as queixas escolares. In: DEL PRETTE, A., DEL PRETTE Z. A. P. (Org.). Habilidades sociais, desenvolvimento e aprendizagem: questões conceituais, avaliação e intervenção. 2. ed. Campinas: Alínea. 20 I4. cap. 9, p. $255-288$.

MELLER, V. A.; TESCHE, L. Vivências corporais de pessoas com deficiência física. Revista Visão Global, Joaçaba, v. 10, n. I, p. 61-84, 2007. Disponível em: editora.unoesc.edu.br/index.php/visaoglobal/article/viewFile/476/22I. Acesso em: 10 ago. 2017.

OLAZ, F. O. Contribuições da teoria sócio-cognitiva de Bandura para o treinamento de habilidades sociais. In: DEL PRETTE, A.; DEL PRETTE, Z. A. P. (Org.). Psicologia das habilidades sociais: diversidade teórica e suas implicações. 3. ed. Petrópolis, RJ: Vozes, 2013.

PAJARES, M. F. Teachers' Beliefs and Educational Research: Cleaning Up a Messy Construct. Review of Educational Research Fall, [S. I.], v. 62, n. 3, p. 307-332, 1992. DOI: https://doi.org/I 0.3102\%2F00346543062003307. Disponível em: https://journals.sagepub.com/doi/abs/10.3102/00346543062003307. Acesso em: 10 ago. 2017.

PINTO, A. da C. Memória, cognição e educação: implicações mútuas. In: DETRY, B.; SIMAS, F. (Eds.). Educação, cognição e desenvolvimento: textos de psicologia educacional para a formação de professores. Lisboa: Edinova, 200I. p. 17-54.

QUITERIO, P. L.; NUNES, L. R. D 'O. de P. Formação de professores em habilidades sociais educativas e inclusivas: guia prático. I. ed. São Paulo: Memnon, 2017.

RIBAS JÚNIOR, R. de C. Cognições de mães brasileiras acerca da paternidade e do desenvolvimento humano: uma contribuição ao estudo da psicologia parental. 2002. Tese (Doutorado em Psicologia Social) - Universidade do Estado do Rio de Janeiro, Rio de Janeiro, 2002.

RODRIGUES, M. C.; DIAS, J. P.; FREITAS, M. F. R. L. Resolução de problemas interpessoais: promovendo o desenvolvimento sociocognitivo na escola. Psicologia em estudo, Maringá, v. I5, n. 4, p. 83I-839, 20I0. Disponível em: http://www.scielo.br/pdf/pe/vI5n4/vI5n4al8.pdf. Acesso em: I0 mar. 2019.

ROSIN-PINOLA, A. R.; DEL PRETTE, Z. A. da P. Inclusão escolar, formação de professores e a assessoria baseada em habilidades sociais educativas. Rev. Bras. Ed., Marília, v. 20, n. 3, p. 34I-356, jul./set. 2014. Disponível em: <https://dx.doi.org//0.1590/SI 4I3-653820I4000300003>. Acesso em: 24 set. 2017. 
SANTOS FILHO, J.C. Pesquisa quantitativa versus Pesquisa qualitativa: o desafio paradigmático. In: SANTOS FILHO, J. C.; GAMBOA, Sílvio Sánchez. (Org.). Pesquisa Educacional: quantidadequalidade. 7. ed. São Paulo: Cortez, 2009. 4 v, p. 13-59. (Coleção Questões da Nossa Época).

SCHOENFELDT, B. K. Técnicas projetivas e expressivas. Os Três Personagens: um novo teste projetivo. Arq. Brasileiro de Psicologia, Rio de Janeiro, v. 3 I, n. 4, p. 67-89, 1979. Disponível em: https://bibliotecadigital.fgv.br/ojs/index.php/abp/article/view//8243. Acesso em: 24 set. 2017.

SEABRA JÚNIOR, L. Educação física e inclusão educacional: entender para atender. 20I2. 220 f. Tese (Doutorado em Educação Física) - Universidade Estadual de Campinas, Campinas, SP, 2012.

SILVA, O. M. da. A epopéia ignorada: pessoa deficiente na história do mundo de ontem e de hoje. I. ed. São Paulo: CEDAS, 1987.

SOUZA, D. P. de. Políticas Públicas e a Visibilidade da Pessoa com Deficiência: Estudo de Caso do Projeto Curupira. 20I4. 196 f. Tese (Doutorado em Educação) - Universidade Federal do Amazonas, Manaus, 20I4. Disponível em: https://tede.ufam.edu.br/handle/tede/4I3I. Acesso em: 24 set. 2017.

SOUZA, L. da C. Formação de professores no curso de Educação Física da UEPA: A inclusão escolar de pessoas com deficiência. 2014. 206 f. Dissertação (Mestrado em Educação) Universidade do Estado do Pará, Belém, 20I4. Disponível em: https://ccse.uepa.br/ppged/wpcontent/uploads/dissertacoes/08/loyana_da_costa_souza.pdf. Acesso em: 24 set. 2017.

SOUZA, P. A. de. Elegilibidade e inclusão pelo esporte adaptado e paraolímpico In: FERREIRA, E. L. (Org.). Atividades Físicas Inclusivas para Pessoas com Deficiência. 2. ed. Niterói: Intertexto. 20II. 210 p.

VIGOTSKY, L. S. A construção do pensamento e da linguagem. I. ed. São Paulo: Martins Fontes, $200 \mathrm{I}$.

Recebido em: 08 de fevereiro de 2021.

Versão corrigida recebida em: 27 de novembro de 2021 .

Aceito em: 27 de novembro de 2021 .

Publicado online em: 18 de fevereiro de 2022.

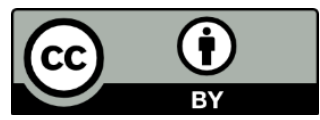

